\title{
The artificial pancreas: Incremental improvements towards an automated closed-loop insulin delivery system in type I diabetes
}

\section{Editorial}

Type 1 diabetes (T1D) is a multifactorial disease and both, an autoimmune disease and a metabolic disorder. The disease itself is characterized by an irreversible T-cell-mediated destruction of $\beta$-cells in the islets of Langerhans of the pancreas, resulting in insulin deficiency. Insulin deficiency leads to disturbances in blood glucose homeostasis, hyperglycemia, increased gluconeogenesis and lipolysis, elevated metabolism of free fatty acids and the generation of ketone bodies. Life-threatening hyperglycemia and diabetic ketoacidosis are the primary clinical signs of T1D while micro vascular and macro vascular complications are the long-term burdens of the disease. Both, immunologic and metabolic changes often far precede the clinical onset and diagnosis of the disease.

The absolute deficiency of insulin secretion in T1D patients requires insulin injections to maintain carbohydrate metabolism and achieve glycemic control. Unfortunately, to date, no cure has been identified to prevent, postpone the onset, halt the further progression or reverse the course of the disease. ${ }^{1}$ Thus, insulin-replacement therapy is the life-saving, first-line treatment for T1D and remains the widely accepted standard of care. ${ }^{2}$ Multiple daily injections or continuous subcutaneous insulin delivery using insulin pumps is the means by which T1D patients aim to restore carbohydrate metabolism and achieve glycemic control. Indeed, multiple studies have demonstrated that intensive insulin therapy and tight glycemic control may prevent acute and chronic complications and reduce morbidity and mortality in T1D patients. ${ }^{3-6}$ However, even intensive insulin-replacement regimens are not always sufficient in restoring euglycemia and achieve recommended $\mathrm{HbAlc}$ levels. ${ }^{78}$ Moreover, they are often associated with the risk of both, symptomatic and lifethreatening hypoglycemia. ${ }^{9-11}$

It is for these reasons that over the last 40 years major efforts were underway, both in academia and industry, to develop and advance novel strategies and technologies in order to restore strict glycemic control and reduce hyperglycemia without increasing the risk for hypoglycemia in patients diagnosed with T1D. More specifically, a significant amount of research, resources and talent were directed at investigating and developing continuous glucose sensors and monitors, automated insulin pumps, and controlled insulin release and delivery systems.

The many technical and incremental improvements of continuous glucose monitoring resulted in studies demonstrating improved glycemic control in T1D patients. ${ }^{12,13}$ This was followed by the development of insulin delivery systems that stop insulin delivery in response to existing, ${ }^{14}$ or predicted,,${ }^{15}$ low sensor glucose values. In particular, it was shown in several studies that the risk of hypoglycemia may be reduced if insulin delivery is linked to sensor glucose levels during the use of an insulin pump that has a thresholdsuspend feature, which temporarily interrupts insulin delivery at
Volume 6 Issue 2 - 2019

\author{
Martina S Burn,' Sabrina C Burn, ${ }^{2}$ Paul Burn ${ }^{3}$ \\ 'Department of Obstetrics, Gynecology, and Reproductive \\ Sciences, Yale School of Medicine, USA \\ ${ }^{2}$ Department of Obstetrics, Gynecology and Women's Health, \\ University of Minnesota, USA \\ ${ }^{3}$ Metabolic and Cardiovascular Health, USA
}

Correspondence: Martina S Burn, Department of Obstetrics, Gynecology, and Reproductive Sciences, New Haven, CT, USA, Email:martina.burn@yale.edu

Received: March II, 2019 | Published: April 15, 2019

preset glucose levels. ${ }^{16,17}$ Safety features such as threshold-suspend and predictive low glucose management insulin pumps provided an important and significant step in the development of device technology. The respective clinical applications appear to be safe and address hypoglycemia; however, using such devices still does not sufficiently address hyperglycemia, the major issue in T1D patients.

More recently, with major advances in microelectronics, glucose sensor technology and insulin delivery systems, the old idea of developing an "artificial pancreas" or a "closed-loop insulin delivery system" that will automate the delivery of insulin linked to actual blood glucose levels has again gotten traction in the scientific community. This multi-device technology is based on using a control algorithm to autonomously, automatically, and continually adjust subcutaneous delivery of insulin based on real-time, subcutaneous glucose sensor data. ${ }^{18,19}$ Its ultimate objective is to relieve T1D patients of the burden of diabetes self-management.

Hybrid closed-loop systems which combine user-delivered premeal boluses with automatic inter-prandial insulin delivery were the first systems developed along this lines..$^{20}$ In 2016, the Center for Devices and Radiological Health of the Food and Drug Administration approved the first hybrid closed-loop system: the Medtronic Mini Med 670G System. According to the manufacturer the Mini Med 670G system is intended for continuous delivery of basal insulin (at user selectable rates) and administration of insulin boluses (in user selectable amounts) for the management of T1D in persons fourteen years of age and older.

Studies have shown that hybrid closed-loop systems are reliable and safe to be used in adults and adolescents. ${ }^{21,22}$ These systems allow patients to lower mean blood glucose levels without increasing the risk of hypoglycemia and they help to improve the proportion of time spent in a normal and healthy glucose range. In addition, extensive studies under controlled laboratory settings and several randomized, controlled outpatient studies have been completed to test various 
insulin-only artificial pancreas closed-loop systems. ${ }^{23-28}$ They all demonstrated that these systems have the potential to improve glucose control and reduce the risk of hypoglycemia. ${ }^{29}$ Studies that investigate the potential of bi-hormonal bionic pancreas systems that combine continuous glucose monitoring and algorithms to automatically administer both insulin and glucagon are thus already underway. ${ }^{30}$

In conclusion, over the last 40 years, considerable progress has been made towards developing continuous glucose sensors, automated insulin delivery devices, and closed-loop artificial pancreas systems that are clinically meaningful and beneficial to a subset of T1D patients under specific conditions. Despite considerable progress, however, many technical, practical and clinical challenges remain towards the development of a fully automated, autonomous closedloop artificial pancreas system. To date, studies assessing safety and efficacy of closed-loop artificial pancreas systems involving patients under at-home, free-living conditions are still very limited in number Moreover, it remains to be established whether a closed-loop artificial pancreas system is feasible, efficacious, and safe to be used in adolescents and children. As important, to fully determine the potential benefit of such technology on restoring glycemic control, normalizing $\mathrm{HbA1c}$ levels, and avoiding acute and chronic complications of diabetes, corresponding data will have to be generated in largescale clinical trials with extended follow-up periods. Last but not least, delivering small technological advancements and providing incremental progress over decades by no means guarantee market acceptance or predict market penetration of a product. While a mature closed-loop artificial pancreas system may be attractive, practical and beneficial for a certain sub-segment of the T1D patient population, it may be completely unattractive, burdensome, and ignored by others. Thus, it remains to be seen how the individual T1D patient, the T1D community, the healthcare providers and the market-place will embrace the closed-loop artificial pancreas technology when it fully matures.

At last, the question remains whether academic talent, resources and funds should continue to be deployed towards incremental improvements of currently existing glucose sensing, glucose monitoring, insulin delivery and closed-loop artificial pancreas technologies, or whether the T1D community would be better served with investments into transformative research and discoveries. For both, academic T1D researchers and T1D funding agencies it may be time to halt and once more reflect and consider the ultimate needs of the T1D community. While incremental improvements in closedloop artificial pancreas technology may undoubtedly benefit and improve quality of life and psychological well-being of a subset of T1D patients, a transformative discovery holds the promise of a cure by restoring glycemic control and normal physiology in all patients diagnosed with T1D.

\section{Acknowledgment}

None.

\section{Conflicts of interests}

Authors declare that there is no conflict of interest.

\section{References}

1. Burn P. Type 1 diabetes. Nat Rev Drug Discov. 2010;9(3):187-188.

2. Burn MS, Burn P. Far from replacing insulin in type 1 diabetes. $J$ Pediatr Neonatal Care. 2015;3(1):108.
3. The Diabetes Control and Complications Trial Research Group. The effect of intensive treatment of diabetes on the development and progression of long-term complications in insulin-dependent diabetes mellitus. $N$ Engl $J$ Med. 1993;329:977-986.

4. Writing Team for the Diabetes Control and Complications Trial/ Epidemiology of Diabetes Interventions and Complications Research Group. Effect of intensive therapy on the microvascular complications of type 1 diabetes mellitus. JAMA. 2002;287:2563-2594.

5. Nathan DM, Cleary PA, Backlund JY, et al. Intensive diabetes treatment and cardiovascular disease in patients with type 1 diabetes. $N$ Engl J Med. 2005;353:2643-2653.

6. Orchard TJ, Nathan DM, Zinman B, et al. Association between 7 years of intensive treatment of type 1 diabetes and long-term mortality. JAMA. 2015;313(1):45-53.

7. Peritti DB, Klingensmith J, Bell RA, et al. Glycemic control in youth with diabetes: the SEARCH for Diabetes in Youth Study. $J$ Pediatr. 2009; 155:668-672.

8. Wood JR, Miller KM, Maahs DM, et al. Most youth with type 1 diabetes in the T1D Exchange Clinic Registry do not meet American Diabetes Association or International Society for Pediatric and Adolescent Diabetes clinical guidelines. Diabetes Care. 2013;36:2035-2037.

9. Cryer PE, Davis SN, Shamoon H. Hypoglycemia in diabetes. Diabetes Care. 2003;26:1902-1912.

10. Cryer PE. The barrier of hypoglycemia in diabetes. Diabetes. 2008;57:3169-3176.

11. The Diabetes Control Complications Trial Research Groups. Hypoglycemia in the Diabetes Control and Complications Trial. Diabetes. 1997;46:271286.

12. Tamborlane WV, Beck RW, Bode BW, et al. Continuous glucose monitoring and intensive treatment of type 1 diabetes. N Engl J Med. 2008:1464-1476.

13. Pickup JC, Freeman SC, Sutton AJ. Glycaemic control in type 1 diabetes during real time continuous glucose monitoring compared with self monitoring of blood glucose: meta-analysis of randomised controlled trials using individual patient data. BMJ. 2011;343:3805.

14. Bergenstal RM, Klonoff DC, Garg SK, et al. Threshold-based insulinpump interruption for reduction of hypoglycemia. $N$ Engl $J$ Med. 2013;369(3):224-232

15. Choudhary P, Olsen BS, Conget I, et al. Hypoglycemia prevention and user acceptance of an insulin pump system with predictive low glucose management. Diabetes Technol Ther. 2016;18(5):288-291.

16. Bergenstal RM, Klonoff DC, Garg SK, et al. Threshold-based insulin-pump interruption for reduction of hypoglycemia. N Engl J Med. 2013:224-232.

17. Buckingham BA, Raghinaru D, Cameron F, et al. Predictive low-glucose insulin suspension reduces duration of nocturnal hypoglycemia in children without increasing ketosis. Diabetes Care. 2015;38:1197-1204.

18. Hovorka R. Closed-loop insulin delivery: from bench to clinical practice. Nat Rev Endocrinol. 2011;7:385-395.

19. Trevitt S, Simpson S, Wood A. Artificial pancreas device systems for the closed-loop control of type 1 diabetes. J Diabetes Sci Technol. 2016;10(3):714-723.

20. Weaver KM, Hirsch IB. The hybrid closed-loop system: evolution and practical applications. Diabetes Technol Ther. 2018;20(2):2-16.

21. Bergenstal RM, Garg S, Weinzimer SA, et al. Safety of a hybrid closedloop insulin delivery system in patients with type 1 diabetes. JAMA. 2016;316(13):1407-1408.

22. Bally L, Thabit H, Hovorka R. Glucose-responsive insulin delivery for 
type 1 diabetes: The artificial pancreas story. International Journal of Pharmaceutics. 2018;544(2):309-318.

23. Kovatchev BP, Renard E, Cobelli C, et al. Safety of outpatient closed-loop control: first randomized crossover trials of a wearable artificial pancreas. Diabetes Care. 2014;37:1789-1796.

24. Leelarathna L, Dellweg S, Mader JK, et al. Day and night home closed-loop insulin delivery in adults with type 1 diabetes: three-center randomized crossover study. Diabetes Care. 2014;37:1931-1937.

25. Thabit H, Tauschmann M, Allen JM, et al. Home use of an artificial beta cell in type 1 diabetes. $N$ Engl J Med. 2015;373:2129-2140.

26. Ly TT, Roy A, Grosman B, et al. Day and night closed-loop control using the integrated Medtronic hybrid closed-loop system in type 1 diabetes at diabetes camp. Diabetes Care. 2015;38:1-8.
27. Del Favero S, Boscari F, Messori M, et al. Randomized summer camp crossover trial in 5- to 9- year-old children: outpatient wearable artificial pancreas is feasible and safe. Diabetes Care. 2016;39:1180-1185.

28. Tauschmann M, Allen JM, Wilinska ME, et al. Day-and-night hybrid closed-loop insulin delivery in adolescents with type 1 diabetes: a freeliving, randomized clinical trial. Diabetes Care. 2016;39:1168-1174.

29. Weisman A, Bai JW, Cardinez M, et al. Effect of artificial pancreas systems on glycemic control in patients with type 1 diabetes: a systematic review and meta-analysis of outpatient randomized controlled trials. The Lancet Diabetes \& Endocrinology. 2017;5(7):501-512.

30. El Khatib FH, Balliro C, Hillard MA, et al. Home use of a bihormonal bionic pancreas versus insulin pump therapy in adults with type 1 diabetes: a multicentre randomised crossover trial. Lancet. 2017;389(10067):369380 . 